\title{
Awareness, Treatment, and Control of Hypertension among the Adult Population in Burkina Faso: Evidence from a Nationwide Population-Based Survey
}

\author{
Kadari Cissé $(\mathbb{D}),{ }^{1,2}$ Seni Kouanda $\left(\mathbb{D},{ }^{2,3}\right.$ Yves Coppieters't Wallant ${ }^{(D)},{ }^{1}$ \\ and Fati Kirakoya-Samadoulougou $\mathbb{( D}^{1}$ \\ ${ }^{1}$ Centre de Recherche en Epidémiologie, Biostatistiques et Recherche Clinique, Ecole de Santé Publique, \\ Université Libre de Bruxelles, Brussels, Belgium \\ ${ }^{2}$ Departement Biomédical et Santé Publique, Institut de Recherche en Sciences de la Santé, Ouagadougou, Burkina Faso \\ ${ }^{3}$ Institut Africain de Santé Publique, Ouagadougou, Burkina Faso
}

Correspondence should be addressed to Kadari Cissé; cisskad4@gmail.com

Received 10 February 2021; Revised 29 August 2021; Accepted 18 September 2021; Published 29 September 2021

Academic Editor: Kai Hu

Copyright $\odot 2021$ Kadari Cissé et al. This is an open access article distributed under the Creative Commons Attribution License, which permits unrestricted use, distribution, and reproduction in any medium, provided the original work is properly cited.

Background. Hypertension is the leading cause of cardiovascular disease, particularly in low- and middle-income countries. Improved awareness of hypertension status can significantly increase early treatment, thereby reducing cardiovascular complications and premature death. This study aimed to report the prevalence of the awareness, treatment, and control of hypertension among the adult population in Burkina Faso. Method. We performed a secondary analysis of the first national population-based survey on common risk factors of noncommunicable diseases in Burkina Faso. It was a national representative cross-sectional survey among adults aged 25-64 years. Awareness of hypertension was defined by blood pressure $\geq 140 / 90 \mathrm{mmHg}$ or a prior diagnosis by a health worker or the use of any antihypertensive drugs. A modified Poisson regression model using a generalized estimating equation was used to identify factors associated with awareness of hypertension. Result. A total of 4628 people with valid blood pressure measurements were considered. Of them, 828 had hypertension. Among people with hypertension, the prevalence of awareness was $17.5 \%$ (95\% CI: $14.4 \%-21.1 \%$ ), and $47.3 \%$ (95\% CI: 37.6\%-57.3\%) of them had taken antihypertensive medications for their hypertension. One-third (35.5\% (95\% CI: $23.3 \%-49.9 \%)$ ) of those who took medications had controlled hypertension. The prevalence of awareness was significantly higher among women (21.1\% (95\% CI: $16.4 \%-26.7 \%)$ ) compared with men (13.8\% (95\% CI: 10.4\%-17.9\%)) $(p=0.019)$. The prevalence of awareness increased with increasing age and education level. Nearly one-third (29.3\% (95\% CI: $25.3 \%-33.6 \%)$ ) of people with hypertension needed antihypertensive drug treatment. Conclusion. There was a poor level of awareness, treatment, and control of hypertension among adults in Burkina Faso. Effective control strategies to increase the screening of hypertension in primary care and at the community level are necessary in Burkina Faso.

\section{Introduction}

Hypertension is the leading cause of cardiovascular diseases (CVDs) worldwide, with at least $22.3 \%$ of CVDs being attributable to hypertension [1]. Nearly 9.4 million global deaths are attributable to hypertension and its complications [2]. In addition to heart complications such as ischemic heart disease, stroke, and heart failure, hypertension causes peripheral vascular diseases and many other vital organ impairments, such as renal or visual complications [3]. Most hypertension-related complications are preventable with lifestyle change strategies combined with antihypertensive drug therapy, which is known to substantially reduce the occurrence of future cardiovascular events [4]. However, hypertension remains an important global public health challenge. The number of cases was estimated to be 1.36 billion in 2010 and will reach 1.56 billion in $2025[5,6]$. Lowand middle-income countries (LMICs) are mostly affected 
[6]. In sub-Saharan Africa (SSA), the number of cases of hypertension was estimated to be 130.2 million in 2010, only one-third of whom were aware of their hypertension; the number is projected to reach 216.8 million by 2030 [7]. Therefore, detection, treatment, and control are recognized as being of high priority for LMICs [6].

Hypertension is a silent and asymptomatic "killer," since there are no symptoms in the early stage of this condition. Severe complications (e.g., stroke, heart attack, and kidney complications) might occur before symptoms appear. Despite the widespread availability of antihypertensive medications, the burden of hypertension and its complications is rising [6]. Unawareness of hypertension delays the early implementation of lifestyle change interventions and antihypertensive treatments to control the rising blood pressure. Improving the awareness among communities is crucial to reduce the delay of treatment initiation and to control the high blood pressure and prevent hypertension-related cardiovascular complications and mortality. In SSA, the public health response in this field is still low, with research findings showing that a high proportion of hypertensive individuals are unaware of their condition [7]. As there are often no symptoms in the early stage, the early detection of hypertension could be done through regular measurements of blood pressure in the community or during each visit to a health center. Few countries have yet to implement a program for hypertension awareness and control or provide guidelines to improve hypertension management at all levels of the health system [4]. Meanwhile, rapid urbanization, the "Western lifestyle," and the increasing number of elderly adults have resulted in the urgency to describe the risk factors that delay the awareness, detection, and treatment of hypertension to help policymakers take effective prevention measures.

In Burkina Faso, there is a high prevalence of hypertension, estimated to be $18.5 \%$ [8]. This prevalence is lower than the mean of SSA (30.8\%) [7]. National representative studies on awareness of hypertension are rare in SSA. Some national representative studies on awareness of hypertension were reported in Kenya (15.6\%), Botswana (46\%) [9], Guinea (24.8\%) [10], and Nigeria (60\%) [11]. As in many others countries in SSA, little is known about the awareness of hypertension among the adult population in Burkina Faso, while, in many countries across SSA, nationwide population-based strategies are urgently needed to improve the awareness of hypertension since it is projected that hypertension will be an important health priority. Many local studies have been done. Indeed, a local study in six health and demographic surveillance systems (HDSS) across SSA, including that of Nanoro (Burkina Faso), reported a prevalence of awareness of $39.9 \%$ in Nanoro, which seems to be lower than that reported in others regions (e.g., Kenya and South Africa) [12]. Another local study in the Kaya HDSS showed that the prevalence of awareness of hypertension was $26.8 \%$ [13]. These local studies are specific to their target population and might not be generalizable to Burkina Faso, since they were conducted among a small surveilled and controlled adult population. Accurate nationwide evidence on hypertension is needed to guide appropriate country- level policy response. The STEPwise survey, conducted in 2013 in Burkina Faso, offered an opportunity to assess the nationwide prevalence and factors that might influence the awareness of hypertension among the adult population in the country. Therefore, our study aimed to examine the prevalence of awareness of hypertension and its associated factors among adults in Burkina Faso. The results might help policymakers to improve hypertension control strategies to achieve national and global goals.

\section{Materials and Methods}

2.1. Study Type and Setting. This research was a secondary analysis of the last national survey on CVD risk factors conducted in 2013 in Burkina Faso. Burkina Faso is located in the SSA region in West Africa, covering a surface area of 272,960 $\mathrm{km}^{2}$ with 20,870,060 habitants in 2019 [14]. The country has two main urban cities (largest cities), namely, Ouagadougou (capital) and Bobo-Dioulasso (economic capital). Life expectancy at birth was 61.6 years in 2019 (https://data.worldbank.org/indicator/SP.DYN. LE00.IN?locations=BF). The proportion of the population living in urban areas increased (according to the results of the last national population census) from $12.7 \%$ in 1985 to $22.7 \%$ in 2006 [15]. The country comprises multiethnic groups (at least 60 ethnic groups) with different cultural practices in terms of demography, education, and alimentation [16, 17]. The ethnic groups are organized depending on the region, which creates natural clusters of sociocultural practices and behaviors related to CVD risk. The epidemiological profile is dominated by infectious diseases, with an increasing burden of noncommunicable diseases (NCDs), including CVDs, resulting in the country facing a double burden of disease and a progressive change of the pattern of diseases. Healthcare is provided by 2819 health facilities (2286 public and 533 private health facilities) grouped in 70 health districts. All health programs, including the NCDs program, are implemented by the health district lead teams. The health district is the first level of health program management.

2.2. Data Source: The STEP Survey. This unique national survey focused on common NCDs risk factors was carried out in 2013. It was a national and regional representative survey that used the World Health Organization (WHO) Stepwise approach and was a descriptive cross-sectional study including people aged 25-64 years, in which random sampling was performed. Cluster-stratified three-stage sampling was applied. In the first stage, 240 primary sampling unit enumeration areas (EAs) (or clusters) were randomly selected, proportionally to the number of households within each stratum (region and residence). The EA list provided from the fourth population and habitat census realized in Burkina Faso in 2006 (updated in 2010 during the Health and Demographic Survey) was used as the EA sampling base. A fixed number (i.e., 20) of the households were selected in each cluster after enumeration of the resident households. The Kish selection 
method was used to select a member of household to participate in the study. A total of 4800 persons were selected using the Kish approach, and from those, 4695 were interviewed; others declined to participate.

The stepwise survey collected much information about NCD risk factors and oral health. All risk factors were collected using the standardized WHO stepwise approach. Data on sociodemographic variables and behavioral cardiovascular risk factors were collected through direct interviews with household participants. The metabolic risk factors were collected through physical and biological measurements. Blood pressure was collected and measured by an electronic device (OMRON HEM-705 brand PC, Tokyo, Japan). The blood pressure was measured three times for each individual using the same device and by the same practitioner at the right arm after $15 \mathrm{~min}$ intervals rest. The participants with a valid measurements of blood pressure were considered in our analysis. The measurement of blood pressure was well described by Soubeiga et al. [8]. The mean of the last two readings was considered for the definition of hypertension.

2.3. Outcome Variable. Our analysis focused on hypertension, defined by blood pressure above or equal to $140 \mathrm{mmHg}$ for systolic pressure and/or $90 \mathrm{mmHg}$ for diastolic pressure or antihypertensive medication intake. The awareness of hypertension was measured during the survey by asking each participant the question, "Have you ever been told by a doctor, nurse, or other healthcare worker that you have hypertension (high blood pressure)?" [12]. The awareness of hypertension was defined by having hypertension and not being previously informed by a doctor, nurse, or other health worker. We also estimated the proportion of adults who had taken antihypertensive medications to treat their hypertension (the antihypertensive treatment was self-reported as formulated in the WHO STEPwise questionnaire). Among adults who took antihypertensive medication, we defined controlled hypertension as when the blood pressure was below $140 / 90 \mathrm{mmHg}$. We reported the proportion of hypertensive adults who had seen a traditional healer or taken traditional medicine. Additionally, we estimated the proportion of people who were not aware of their hypertension, even if they needed drug therapy, based on the WHO risk stratification approach for hypertension management [18].

\subsection{Explanatory Variables}

2.4.1. Sociodemographic Variables. Based on previous studies using the same data $[8,19,20]$ and other studies in SSA [21-24], we used the following variables as individual-level explanatory variables: age, sex, education, occupation status, and residence. Participants age was categorized into four groups (25-34, 35-44, 45-54, and 55-64 years). The sex variable was coded as 0 for "women" and 1 for "men." For education level, attending formal school was considered and categorized into three groups (unschooled, primary, secondary and more). The occupation status was categorized into three groups $(1=$ "wage earner," 2 = "self-employed," and 3 ="jobless"). The residence of the participants was classified in two groups ( 1 = "urban" and 2 = "rural").

2.4.2. Other Cardiovascular Risk Factors. Tobacco use was focused on current smoking. Alcohol consumption in this study corresponded to usual alcohol consumption within 30 days given by the question, "Have you drunk an alcoholic drink in the last 30 days?" Optimal fruit and legume consumption corresponded to at least five portions of fruit and/or legumes consumed a day. For physical activity, we computed this category using the WHO's analysis guidelines: the variable was categorized into three groups $(1=$ "intensive physical activity," 2 ="moderate physical activity," and 3 = "low physical activity"). Body mass index (BMI) was classified into four groups, as recommended by WHO (1 = "underweight," 2 = "normal weight," 3 = "overweight," and $4=$ "obese"). The raised blood glucose was defined by capillary glycaemia as above or equal to $6.1 \mathrm{mmol} / \mathrm{L}$. Based on the current guidelines, diabetes may be diagnosed based on plasma glucose criteria, either the fasting plasma glucose (FPG) value or the 2-h plasma glucose (2-h PG) value during a 75-g oral glucose tolerance test (OGTT), or A1C criteria [25]. Impaired fasting glucose (IFG) is defined as FPG levels from 100 to $125 \mathrm{mg} / \mathrm{dL}$ (from 5.6 to $6.9 \mathrm{mmol} / \mathrm{L}$ ) [25]. So, it may be described based on capillary fasting blood glucose as "the raised fasting blood glucose" defined by capillary glycaemia above or equal to $6.1 \mathrm{mmol} / \mathrm{L}[26,27]$. Hypercholesterolemia was defined by capillary total cholesterol above or equal to $5.2 \mathrm{mmol} / \mathrm{L}$.

2.5. Statistical Method. We first described the characteristics of the study population. We then evaluated the overall prevalence of awareness, included by sociodemographic and cardiovascular risk factors. For the treatment and control of hypertension, we reported the national prevalence without disaggregation by subgroups, since the numbers of treated and controlled hypertension cases were small. The chisquare test was used to check for differences in the prevalence of awareness by characteristics. A modified Poisson regression model using a generalized estimating equation (GEE) was implemented to derive the prevalence ratios (PRs) with robust variance while taking into account the clustering of observations. The univariate and multivariable GEE was applied to individual-level covariates using enumeration area identity as the clustering variable. PRs with 95\% confidence intervals were calculated, and statistical significance at the $5 \%$ level $(p<0.05)$ was considered.

\section{Results}

3.1. Background Characteristics of the Study Population. As shown in Figure 1, a total of 4628 participants had valid measurements of blood pressure, and 828 of them had hypertension as defined by WHO.

As shown in Table 1, half of the participants with hypertension were female, $22.2 \%$ were at least 55 years old, $10.5 \%$ had attended at least secondary school, and $61.9 \%$ were rural residents. Regarding cardiovascular behavioral, 


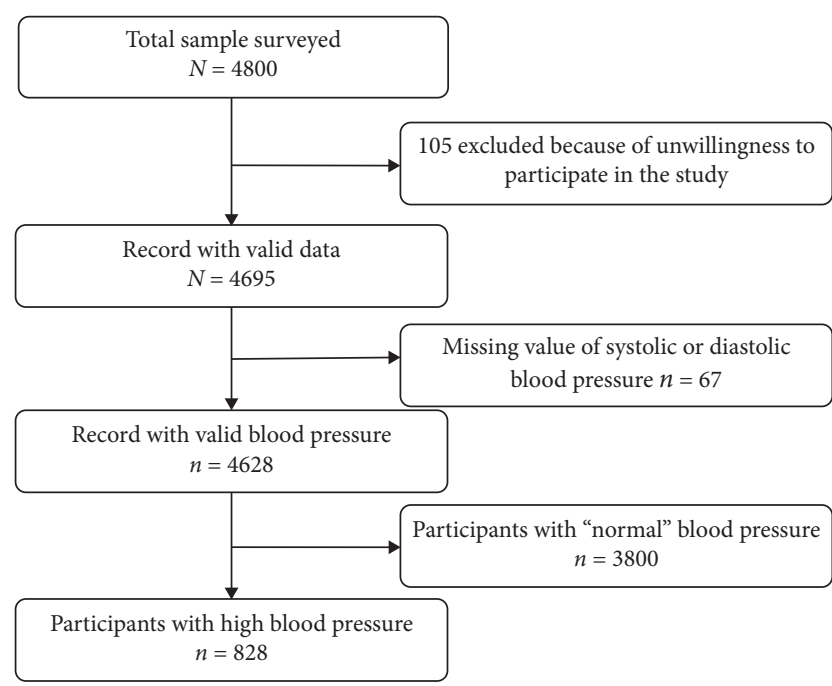

FIGURE 1: Flowchart of the study participants.

and biological profiles, $9.3 \%$ of the adults with hypertension were current smokers, nearly one-third (30.1\%) were current alcohol drinkers, $11.5 \%$ were obese, and $8.7 \%$ had raised blood glucose (Table 1).

3.2. Prevalence of Awareness of Hypertension. Awareness was evaluated among the participants with hypertension. Table 2 shows the prevalence of awareness of hypertension by sociodemographic, behavioral, and biological characteristics. The prevalence of awareness of hypertension was $17.5 \%$ (95\% CI: 14.3-21.1). This prevalence was $21.1 \%$ (95\% CI: 16.4-26.7) among women and 13.8\% (95\% CI: 10.4-17.9) among men. Regarding age groups, the prevalence of awareness of hypertension was 10.1\% (95\% CI: 5.9-16.8) for the 25-34 year olds, 9.6\% (95\% CI: 6.2-14.6) for the 35-44 year olds, $20.1 \%$ (95\% CI: 14.5-27.2) for the 45-54 year olds, and $32.0 \%$ (95\% CI: 24.9-39.9) for the 55-64 year olds. The prevalence of awareness of hypertension increased with education level-3.6\% (95\% CI: 10.7-17.1) for adults who had not attended formal school, 23.0\% (95\% CI: 15.2-33.2) for adults who had attended primary school, and 35.1\% (95\% CI: 25.6-46.0) for adults who had attended at least secondary school. One-quarter (24.3\% (95\% CI: 18.6-31.1)) of the adults who lived in urban areas were aware of their hypertension. This prevalence decreased to $13.2 \%$ (95\% CI: 10.3-16.8) in rural areas. Regarding behavioral and biological profiles, the prevalence of awareness was $9.6 \%$ (95\% CI: 4.2-20.6) among current smokers, 45.6\% (95\% CI: 31.1-61.0) among obese adults, and 26.3\% (95\% CI: 15.7-40.7) among adults with raised blood glucose (Table 2).

3.3. Factors Associated with Awareness of Hypertension. Table 2 presents the factors associated with awareness among hypertensive adults. After adjusting for all variables in Table 1, we found that age, education level, and obesity were significantly associated with awareness.
TABLE 1: Sociodemographic, behavioral, and biological risk factor profiles of the study population.

\begin{tabular}{|c|c|c|}
\hline Characteristics & Number & Percentage \\
\hline \multicolumn{3}{|l|}{ Sex } \\
\hline Women & 389 & 50.4 \\
\hline Men & 439 & 49.6 \\
\hline \multicolumn{3}{|l|}{ Age group, years } \\
\hline $25-34$ & 230 & 25.1 \\
\hline $35-44$ & 211 & 26.5 \\
\hline $45-54$ & 201 & 26.2 \\
\hline $55-64$ & 186 & 22.2 \\
\hline \multicolumn{3}{|l|}{ Marital status } \\
\hline Single & 160 & 17.6 \\
\hline Married & 668 & 82.4 \\
\hline \multicolumn{3}{|l|}{ Completed level of education } \\
\hline No formal school & 612 & 72.5 \\
\hline Primary school & 128 & 17.0 \\
\hline Secondary or higher & 88 & 10.5 \\
\hline \multicolumn{3}{|l|}{ Profession } \\
\hline Wage earner & 66 & 8.1 \\
\hline Self-employed & 564 & 64.8 \\
\hline Jobless & 198 & 27.1 \\
\hline \multicolumn{3}{|l|}{ Residence } \\
\hline Urban & 256 & 38.1 \\
\hline Rural & 572 & 61.9 \\
\hline \multicolumn{3}{|l|}{ Current smoker } \\
\hline No & 743 & 90.7 \\
\hline Yes & 85 & 9.3 \\
\hline \multicolumn{3}{|l|}{ Current drinker } \\
\hline No & 569 & 69.0 \\
\hline Yes & 259 & 31.0 \\
\hline \multicolumn{3}{|l|}{ Fruit and vegetable intake } \\
\hline$<5$ & 788 & 95.6 \\
\hline$\geq 5$ & 40 & 4.4 \\
\hline \multicolumn{3}{|l|}{ Physical activity } \\
\hline Intense & 451 & 54.2 \\
\hline Moderate & 210 & 25.0 \\
\hline Low & 167 & 20.8 \\
\hline \multicolumn{3}{|l|}{ BMI class } \\
\hline Underweight & 74 & 8.7 \\
\hline Normal & 502 & 58.5 \\
\hline Overweight & 163 & 21.3 \\
\hline Obese & 89 & 11.5 \\
\hline \multicolumn{3}{|l|}{ Raised blood glucose } \\
\hline No & 753 & 91.3 \\
\hline Yes & 75 & 8.7 \\
\hline \multicolumn{3}{|l|}{ Hypercholesterolemia } \\
\hline No & 777 & 93.2 \\
\hline Yes & 51 & 6.8 \\
\hline
\end{tabular}

BMI: body mass index.

Indeed, awareness increased with age: individuals aged 55-64 years had 3.5 times higher prevalence of the awareness compared to those who were aged 25-34 years. Individuals who had attended secondary school or more had 2.5 times (adjusted Prevalence Ratio (aPR): 2.52 (95\% CI: 1.39-4.57)) higher prevalence of the awareness than those who had not attended formal school. Obese individuals had at least four times (aPR: 4.25 (95\% CI: 
TAвLE 2: Prevalence and results of multivariable modified Poisson regression of hypertension awareness among hypertensive adults in Burkina Faso.

\begin{tabular}{|c|c|c|c|c|c|c|c|}
\hline \multirow{2}{*}{ Characteristics } & \multicolumn{7}{|c|}{ Awareness of hypertension } \\
\hline & $N$ & $n$ & Prevalence \% [95\% CI] & Crude PR [95\% CI] & $p$ value & Adjusted PR [95\% CI] & $p$ value \\
\hline All & 828 & 143 & $17.5[14.3-21.1]$ & & & & \\
\hline Sex & & & & & 0.025 & & 0.35 \\
\hline Women & 389 & 82 & $21.1[16.4-26.7]$ & 1 & & 1 & \\
\hline Men & 439 & 61 & $13.8[10.4-17.9]$ & $0.68[0.48-0.95]$ & & $0.82[0.55-1.23]$ & \\
\hline Age group, years & & & & & $<0.001$ & & $<0.001$ \\
\hline $25-34$ & 230 & 20 & $10.1[5.9-16.8]$ & 1 & & 1 & \\
\hline $35-44$ & 211 & 23 & $9.6[6.2-14.6]$ & $1.18[0.66-2.11]$ & & $1.17[0.63-2.13]$ & \\
\hline $45-54$ & 201 & 45 & $20.1[14.5-27.2]$ & $2.18[1.29-3.68]$ & & $2.34[1.37-4.01]$ & \\
\hline $55-64$ & 186 & 55 & $32.0[24.9-39.9]$ & $3.01[1.81-5.00]$ & & $3.59[2.10-6.14]$ & \\
\hline Marital status & & & & & 0.68 & & 0.87 \\
\hline Single & 160 & 32 & $19.6[12.6-29.2]$ & 1 & & 1 & \\
\hline Married & 668 & 111 & $17.0[13.7-20.9]$ & $0.92[0.61-1.39]$ & & $1.03[0.68-1.57]$ & \\
\hline Completed level of education & & & & & $<0.001$ & & 0.009 \\
\hline No formal school & 612 & 85 & $13.6[10.7-17.1]$ & 1 & & 1 & \\
\hline Primary school & 128 & 25 & $23.0[15.2-33.2]$ & $1.34[0.84-2.11]$ & & $1.37[0.84-2.25]$ & \\
\hline Secondary or higher & 88 & 33 & $35.1[25.6-46.0]$ & $2.45[1.57-3.79]$ & & $2.52[1.39-4.57]$ & \\
\hline Profession & & & & & 0.006 & & 0.58 \\
\hline Wage earner & 66 & 20 & $22.2[14.2-32.8]$ & 1 & & 1 & \\
\hline Self-employed & 564 & 76 & $13.4[10.3-17.3]$ & $0.51[0.29-0.86]$ & & $0.82[0.42-1.63]$ & \\
\hline Jobless & 198 & 47 & $25.7[19.3-33.4]$ & $0.84[0.49-1.47]$ & & $1.04[0.54-1.99]$ & \\
\hline Residence & & & & & 0.029 & & 0.22 \\
\hline Urban & 256 & 62 & $24.3[18.6-31.1]$ & 1 & & 1 & \\
\hline Rural & 572 & 81 & $13.2[10.3-16.8]$ & $0.62[0.40-0.95]$ & & $1.35[0.83-2.21]$ & \\
\hline Current smoker & & & & & 0.043 & & 0.68 \\
\hline No & 743 & 136 & $18.3[15.0-22.1]$ & 1 & & 1 & \\
\hline Yes & 85 & 7 & $9.6[4.2-20.6]$ & $0.46[0.21-0.97]$ & & $0.85[0.37-1.89]$ & \\
\hline Current drinker & & & & & 0.75 & & 0.39 \\
\hline No & 569 & 101 & $18.0[14.2-22.6]$ & 1 & & 1 & \\
\hline Yes & 259 & 42 & $16.2[11.8-21.8]$ & $0.94[0.65-1.36]$ & & $0.84[0.57-1.25]$ & \\
\hline Fruit and vegetable intake & & & & & 0.21 & & 0.14 \\
\hline$<5$ & 788 & 132 & $17.1[13.9-20.8]$ & 1 & & 1 & \\
\hline$\geq 5$ & 40 & 11 & $25.2[12.5-44.3]$ & $1.51[0.78-2.90]$ & & $1.62[0.85-3.08]$ & \\
\hline Physical activity & & & & & 0.068 & & 0.72 \\
\hline Intense & 451 & 63 & $13.7[10.4-17.9]$ & 1 & & 1 & \\
\hline Moderate & 210 & 41 & $20.6[14.6-28.4]$ & $1.63[0.91-2.09]$ & & $1.14[0.75-1.72]$ & \\
\hline Low & 167 & 39 & $23.5[16.9-31.7]$ & $1.63[1.06-2.50]$ & & $0.95[0.60-1.51]$ & \\
\hline BMI class & & & & & $<0.001$ & & $<0.001$ \\
\hline Underweight & 74 & 7 & $9.5[4.4-19.5]$ & 1 & & 1 & \\
\hline Normal & 502 & 61 & $11.5[8.7-15.0]$ & $1.25[0.58-2.69]$ & & $1.57[0.71-3.46]$ & \\
\hline Overweight & 163 & 38 & $21.9[16.1-29.1]$ & $2.24[1.01-4.97]$ & & $2.67[1.17-6.11]$ & \\
\hline Obese & 89 & 37 & $45.6[31.1-61.0]$ & $4.09[1.84-9.12]$ & & $4.25[1.81-10.02]$ & \\
\hline Raised blood glucose & & & & & 0.45 & & 0.80 \\
\hline No & 753 & 125 & $16.6[13.3-20.5]$ & 1 & & 1 & \\
\hline Yes & 75 & 18 & $26.3[15.7-40.7]$ & $1.23[0.72-2.11]$ & & $0.93[0.54-1.61]$ & \\
\hline Hypercholesterolemia & & & & & $<0.001$ & & 0.26 \\
\hline No & 777 & 122 & 42.7 [27.9-58.9] & 1 & & 1 & \\
\hline Yes & 51 & 21 & $15.6[12.9-18.9]$ & $0.42[0.26-0.68]$ & & $0.74[0.43-1.26]$ & \\
\hline
\end{tabular}

$N$ : total number of participants with hypertension; $n$ : number of participants who were aware of their hypertension; PR: prevalence ratio; CI: confidence interval.

1.81-10.02)) higher prevalence of the awareness than those who were underweight.

3.4. Treatment and Control of Hypertension. Among adults who were aware of their hypertension, $47.3 \%$ (95\% CI:
37.6-57.3) reported antihypertensive medication prescribed by a doctor or other health worker. One-third (35.5\% (95\% CI: 23.3-49.9)) of those who took medication had controlled their hypertension. Nearly one-third (29.3\% (95\% CI: 25.3-33.6)) of people who were not aware of their hypertension needed antihypertensive drug treatment according 
to WHO guidelines for cardiovascular risk management. This proportion was $27.3 \%$ (95\% CI: $21.9-33.3$ ) for women and 31.1 (95\% CI: $25.4-37.4)$ for men $(p=0.35)$. In urban areas, this figure was $34.1 \%$ (95\% CI: $27.3-41.5)$, and for rural areas, it was $26.7 \%$ (95\% CI: 21.9-31.2) $(p=0.097)$. We noted that $13.9 \%$ (95\% CI: 8.2-22.6) of the adults who were aware their hypertension had seen a traditional healer, and 11.6\% (95\% CI: 6.7-19.6) were taking herbal or traditional remedy.

\section{Discussion}

4.1. Key Findings. This study provides the country-level representative prevalence of awareness of hypertension among the adult population in Burkina Faso, which is one of the lowest-income countries in the world with a high prevalence of hypertension and of other cardiovascular risk factors, as shown by the first STEPwise survey and its related published papers $[8,19,20,28]$. In this study, we found that only $17.5 \%$ of hypertensive adults were aware of their condition. The prevalence of awareness of hypertension was higher among the elderly population, people with more education, and those who were obese. Nearly half $(47.3 \%)$ of the hypertensive adults with awareness of their condition had received treatment for their hypertension, and only one-third (35.5\%) of them had their hypertension controlled.

4.2. Prevalence of Awareness. The prevalence of awareness in our population was lower compared to the overall prevalence in SSA reported by Adeloye and Basquill [7] in a systematic review, which was estimated to be $33.7 \%$. The overall prevalence of awareness of hypertension in low-income countries (LICs) was estimated to be $40.8 \%$ [29]. A recent study in Kenya using the 2015 Kenya STEP survey data reported a prevalence of awareness of hypertension of $15.6 \%$ in Kenya [30]. Using the STEP survey, the prevalence of awareness was $24.8 \%$ in 2016 in Guinea [10]. In Nigeria, a nationwide survey in 2017 showed that six out of every 10 hypertensive patients (60\%) were aware of their status [11]. In Botswana, in 2014, $46 \%$ of hypertensive adults were aware of their hypertensive status [9]. These results in SSA show an important variability in the awareness of hypertension across countries. However, compared to high- and middleincome countries, the overall prevalence of awareness of hypertension remains lower in LICs [29]. Hypertension detection is also lower in LICs, despite its prioritization by many global organizations. The control of hypertension is also recognized to be lower in such countries, despite the availability of effective antihypertensive medications [29]. This situation might be explained by the fact that few individuals in such countries have access to routine blood pressure checks due to poor access to healthcare and hypertension screening programs [29]. The lower rate of awareness of hypertension reported in this study reflects the poor capacity of the health system of the country to manage hypertension. Hypertension remains underdiagnosed among adults in Burkina Faso, despite the availability of self- measurement tools, and it is still poorly screened, even in healthcare centers [30]. Studies in HDSS have reported a higher prevalence of awareness of hypertension $(39.9 \%$ in Nanoro [12] and 26.8\% in Kaya [13]) compared to ours, because the populations of HDSS are subjects of many and regular medical research efforts, which might contribute to increasing their awareness of their health conditions. Regarding the negative effects of unawareness of hypertension on the current rising burden of cardiovascular diseases, it is crucial to pay attention to hypertension screening among the adult population in Burkina Faso. Task sharing with nonphysician healthcare workers (including community health workers) for the screening of hypertension might be an effective solution, since a recent meta-analysis reported the benefit of this intervention on the effective management of blood pressure [31, 32].

4.3. Associated Factors of Awareness. This study reported that, after adjusting for sociodemographic variables and cardiovascular risk factors, the awareness of hypertension was higher among the elderly population, obese adults, and people with more education, which is in accordance with the research findings in the context of low-income countries. Many studies have reported a high prevalence of awareness of hypertension among elderly and obese people $[3,10,11,33,34]$. This finding might be explained by the higher utilization of healthcare services and frequent contact with health centers due to the frequent deterioration of their health [33]. The frequent contact with health centers might also explain the high prevalence of awareness of hypertension among women, even if this relationship disappeared when adjusting for other sociodemographic and risk factor variables. Low-level education was associated with a lower rate of awareness of hypertension, and this finding is consistent with the results of the Prospective Urban Rural Epidemiology (PURE) study in low-income countries that highlighted a lower rate of awareness of hypertension among people with primary or no education [29]. The lack of knowledge about hypertension and its complications [29], low socioeconomic status, and access to healthcare might explain the high rate of unawareness among people with no education, suggesting a future high burden of hypertensionrelated cardiovascular disease among this population. In our study, the awareness of hypertension was higher in urban areas. Evidence from the PURE study shows that, in lowincome countries, the awareness of hypertension is higher in urban areas compared to rural areas [29]. Meanwhile, these differences were not highlighted in middle- and high-income countries, suggesting inequities in access to hypertension management healthcare in LICs such as Burkina Faso.

4.4. Treatment and Control of Hypertension. This study reported that half of the participants aware of their hypertension did not take antihypertensive medication, and nearly two-thirds of them had not controlled their hypertension. This finding is consistent with studies conducted in many LIC contexts $[10,29,33]$. The lower rate of 
treatment of hypertension in LICs, including those reported in this study, is due - as noted by Yaya Bocoum and Hartwig to the low access to hypertension-related healthcare (distance to health facilities, cost to see physicians, cost of medication, etc.), since universal healthcare coverage or health insurance does not usually include severe and chronic illnesses such as hypertension [35]. This situation may encourage herbal or traditional medicine use to treat hypertension and delay an effective management of hypertension. In SSA, a review showed that $47.5 \%$ of adults with hypertension had concomitantly used herbal or traditional medicine and allopathic medicine [36]. A similar proportion $(40,3 \%)$ was reported by Camara et al. [10] in Guinea in 2016 (using STEPwise survey data). Our study noted that one-tenth hypertensive adults had taken traditional medicine. Our study also noted that nearly onethird of hypertensive adults needed drug treatment, according to the WHO guidelines for cardiovascular risk management [18]. The 10-year cardiovascular risk strata were defined using the Framingham global risk score, since this risk score is the only risk score that covers a large number of complications pertaining to hypertension (including ischemic heart disease, stroke, peripheral vascular disease, heart attack, or heart failure) [37]. This risk score is also commonly used in clinical practice in Burkina Faso $[38,39]$. A new approach to address the gap in hypertension treatment is needed. The approach could include the development of national guidelines, the strengthening of antihypertensive medication availability and affordability, the training of healthcare providers, and the shifting of the screening and follow-up of treatment of hypertension to nonphysician health workers or community health workers, since these categories of health workers have shown their effectiveness in hypertension management [31, 32].

4.5. Strengths and Limitations. The main limitation of this study was the measurement of blood pressure in a single visit, which might have overestimated the number of individuals with high blood pressure. The ambulatory monitoring of blood pressure is recognized to predict the risk for morbidity more accurately than a single measurement of blood pressure [40]. The findings presented in this study are specific to adults aged 25-64 years. They may not be extrapolated to adults under 25 years or over 64 years old. In addition, due to its cross-sectional design, the findings of this study might not be considered to derive the causality. Even with the lower level of controlled hypertension in this study, this finding might be affected by the patients' previous experience of medications for other conditions, which might have contributed to their adherence to antihypertensive treatment. The main strength of this study is that it was a nationally representative estimation of awareness of hypertension. We recognize that seven years have elapsed since the first STEPwise survey in Burkina Faso, and the data used for this analysis need to be updated. However, our study provides baseline data for future assessment of the impact of the national noncommunicable disease program, which was drafted in 2016 [41].

\section{Conclusion}

This study is the first nationally representative estimation of awareness of hypertension and its treatment and control in Burkina Faso. The findings suggest a lower prevalence of awareness, treatment, and control, as shown in many other previous studies in low-income countries. We also noted that the elderly, those with more education, and obese people had a higher prevalence of awareness of hypertension. This study shows a national picture of hypertension, before starting any efforts to manage NCDs in the country, which might offer an opportunity to better understand the impact of the national NCD program initiated in 2016 on the hypertension burden. While waiting for a new STEPwise survey in Burkina Faso, these findings might guide policymakers for effective management of hypertension in the country, which might start by better screening people with hypertension through real task sharing with nonphysicians or community health workers. Nevertheless, more studies should be needed to show the best way to improve awareness, treatment, and control of hypertension in the low resource setting, since hypertension is rising in such context and suggesting a future epidemic of hypertension-related complications like cardiovascular diseases.

\section{Data Availability}

The data used to support the findings of this study are available at the Ministry of Health upon request to Bicaba Brice (bicaba_brico@yahoo.fr) or Zoma Torez (torezo2000@ yahoo.fr). All survey materials are available on the WHO website (https://extranet.who.int/ncdsmicrodata/index.php/ catalog).

\section{Ethical Approval}

Before collecting the data in the field, the survey protocol was approved by the Ministry of Health's Ethics Committee for Health Research and the Ministry of Scientific Research and Innovation (Deliberation no. 2012-12-092 of December $05,2012)$. The confidentiality of the information collected was mentioned in the informed consent form.

\section{Consent}

Informed consent was required before the participation of any individual selected for the investigation.

\section{Conflicts of Interest}

The authors declare that they have no conflicts of interest.

\section{Authors' Contributions}

K. C. analyzed the data, interpreted the results, and wrote the first draft of the manuscript with inputs from S. K., YCW, and F. K. S.; F. K. S. conceptualized and formulated the research goals and objectives, led the methodology, and interpreted the results. All authors reviewed, edited, and approved the final version of the manuscript. 


\section{Acknowledgments}

This work was supported by the Academie de Recherche et d'Enseignement Supérieur (ARES) of Belgium in the context of a research program for development focused on cardiovascular diseases in Burkina Faso. The program, named CARDIOPEV, is managed by the Institut de Recherche en Sciences de la Santé (IRSS) in Burkina Faso and Université Libre de Bruxelles in Belgium.

\section{References}

[1] S. Yusuf, P. Joseph, S. Rangarajan et al., "Modifiable risk factors, cardiovascular disease, and mortality in 155722 individuals from 21 high-income, middle-income, and lowincome countries (PURE): a prospective cohort study," The Lancet, vol. 395, no. 10226, pp. 795-808, 2020.

[2] S. S. Lim, T. Vos, and A. D. Flaxman, "A comparative risk assessment of burden of disease and injury attributable to 67 risk factors and risk factor clusters in 21 regions, 1990-2010: a systematic analysis for the global burden of disease study 2010," The Lancet, vol. 380, pp. 2224-2260, 2012.

[3] S. Singh, R. Shankar, and G. P. Singh, "Prevalence and associated risk factors of hypertension: a cross-sectional study in urban varanasi," International Journal of Hypertension, vol. 2017, Article ID 5491838, 10 pages, 2017.

[4] A. Dzudie, B. Rayner, D. Ojji et al., "Roadmap to achieve 25\% hypertension control in Africa by 2025," Cardiovascular Journal of Africa, vol. 28, pp. 262-272, 2017.

[5] P. M. Kearney, M. Whelton, K. Reynolds, P. Muntner, P. K. Whelton, and J. He, "Global burden of hypertension: analysis of worldwide data," The Lancet, vol. 365, no. 9455, pp. 217-223, 2005.

[6] K. T. Mills, A. Stefanescu, and J. He, "The global epidemiology of hypertension," Nature Reviews Nephrology, vol. 16, no. 4, pp. 223-237, 2020.

[7] D. Adeloye and C. Basquill, "Estimating the prevalence and awareness rates of hypertension in Africa: a systematic analysis," PLoS One, vol. 9, no. 8, Article ID e104300, 2014.

[8] J. K. Soubeiga, T. Millogo, B. W. Bicaba, B. Doulougou, and S. Kouanda, "Prevalence and factors associated with hypertension in Burkina Faso: a countrywide cross-sectional study," BMC Public Health, vol. 17, no. 1, 64 pages, 2017.

[9] N. M. Tapela, L. Clifton, G. Tshisimogo et al., "Prevalence and determinants of hypertension awareness, treatment, and control in Botswana: a nationally representative populationbased survey," International Journal of Hypertension, vol. 2020, Article ID 8082341, 12 pages, 2020.

[10] A. Camara, N. M. Baldé, M. Diakité et al., "High prevalence, low awareness, treatment and control rates of hypertension in Guinea: results from a population-based STEPS survey," Journal of Human Hypertension, vol. 30, no. 4, pp. 237-244, 2016.

[11] A. N. Odili, B. S. Chori, B. Danladi et al., "Prevalence, awareness, treatment and control of hypertension in Nigeria: data from a nationwide survey 2017," Global Heart, vol. 15, no. 1, 47 pages, 2020.

[12] F. X. Gómez-Olivé, S. A. Ali, F. Made et al., "Regional and sex differences in the prevalence and awareness of hypertension: an H3Africa AWI-gen study across 6 sites in sub-saharan Africa," Global Heart, vol. 12, no. 2, pp. 81-90, 2017.

[13] B. Doulougou, S. Kouanda, G. H. Ouédraogo, B. I. Meda, A. Bado, and M. V. Zunzunegui, "Awareness, treatment, control of hypertension and utilization of health care services following screening in the North-central region of Burkina Faso," The Pan African Medical Journal, vol. 19259 pages, 2014.

[14] INSD, Projection Démographique de 2007 à 2020 Par Région et Province, Ministère de l'Economie et des Finances, Ouagadougou, Burkina Faso, 2009.

[15] D. Ardjouma, Theme 09: la Croissance Urbaine au Burkina Faso, Ministère de l'Economie et des Finances, Ouagadougou, Burkina Faso, 2009, http://www.cns.bf/IMG/pdf/theme_9_ urbanisation_fin_f.pdf.

[16] R. Héron, Les mangeurs urbains burkinabè, entre satisfaction et sécurisation alimentaires, Ph.D thesis, Université PanthéonSorbonne, Paris, France, 2016.

[17] J.-F. Kobiane and M. Pilon, "Appartenance ethnique et scolarisation au Burkina Faso: la dimension culturelle en question," in Proceedings of the Colloque international de l'AIDELF Démographie et cultures, Québec, Canada, August 2008.

[18] World Health Organization, Prevention of Cardiovascular Disease: Guidelines for Assessment and Management of Cardiovascular Risk, World Health Organization, Geneva, Switzerland, 2007.

[19] T. Millogo, B. W. Bicaba, J. K. Soubeiga, E. Dabiré, I. Médah, and S. Kouanda, "Diabetes and abnormal glucose regulation in the adult population of Burkina Faso: prevalence and predictors," BMC Public Health, vol. 18, no. 1, 350 pages, 2018.

[20] B. Bonnechère, K. Cissé, T. Millogo et al., "Tobacco use and associated risk factors in Burkina Faso: results from a population-based cross-sectional survey," BMC Public Health, vol. 19, no. 1, 2019.

[21] R. G. Wamai, A. P. Kengne, and N. Levitt, "Non-communicable diseases surveillance: overview of magnitude and determinants in Kenya from STEPwise approach survey of 2015," BMC Public Health, vol. 18, no. S3, 2018.

[22] C. Ngaruiya, H. Abubakar, D. Kiptui et al., "Tobacco use and its determinants in the 2015 Kenya WHO STEPS survey," BMC Public Health, vol. 18, no. S3, 2018.

[23] D. A. Amugsi, Z. T. Dimbuene, B. Mberu, S. Muthuri, and A. C. Ezeh, "Prevalence and time trends in overweight and obesity among urban women: an analysis of demographic and health surveys data from 24 African countries, 1991-2014," BMJ Open, vol. 7, Article ID e017344, 2017.

[24] B. Doulougou, S. Kouanda, A. Bado, L. Nikièma, and M. V. Zunzunegui, "Hypertension in the adult population of Kaya health and demographic surveillance system in Burkina Faso: prevalence and associated factors," International Journal of Tropical Disease and Health, vol. 4, pp. 94-110, 2013.

[25] A. D. Association, "2. Classification and diagnosis of diabetes: standards of medical care in diabetes-2020," Diabetes Care, vol. 43, no. Supplement 1, pp. S14-S31, 2020.

[26] World Health Organization and International Diabetes Federation, Definition and Diagnosis of Diabetes Mellitus and Intermediate Hyperglycaemia: Report of a WHO/IDF Consultation, WHO, Geneva, Switzerland, 2006.

[27] World Health Organization, WHO Steps Surveillance Manual: The WHO Stepwise Approach to Chronic Disease Risk Factor Surveillance, WHO, Geneva, Switzerland, 2005.

[28] S. Kaboré, T. Millogo, J. K. Soubeiga, H. Lanou, B. Bicaba, and S. Kouanda, "Prevalence and risk factors for overweight and obesity: a cross-sectional countrywide study in Burkina Faso," BMJ Open, vol. 10, no. 11, Article ID e032953, 2020.

[29] C. K. Chow, K. K. Teo, and S. Rangarajan, "Prevalence, awareness, treatment, and control of hypertension in rural 
and urban communities in high-, middle-, and low-income countries," Journal of the American Medical Association, vol. 310, no. 9, pp. 959-968, 2013.

[30] J. K. Kologo, A. R. Yaméogo, B. Ouedraogo et al., "Population screening contribution in the management of hypertension in koudougou," OALib Journal, vol. 3, no. 12, pp. 1-9, 2016.

[31] T. N. Anand, L. M. Joseph, A. V. Geetha, D. Prabhakaran, and P. Jeemon, "Task sharing with non-physician health-care workers for management of blood pressure in low-income and middle-income countries: a systematic review and metaanalysis," The Lancet Global Health, vol. 7, no. 6, pp. e761-e771, 2019.

[32] G. Ogedegbe, J. Gyamfi, J. Plange-Rhule et al., "Task shifting interventions for cardiovascular risk reduction in low-income and middle-income countries: a systematic review of randomised controlled trials," BMJ Open, vol. 4, no. 10, Article ID e005983, 2014.

[33] S. F. Mohamed, M. K. Mutua, R. Wamai et al., "Prevalence, awareness, treatment and control of hypertension and their determinants: results from a national survey in Kenya," $B M C$ Public Health, vol. 18, no. S3, 1219 pages, 2018.

[34] R. Y. Raheem, A. Taiwo, and G. Oye, "Awareness of hypertension and its impact on blood pressure control among elderly nigerians: report from the Ibadan study of aging," Pan African Medical Journal, vol. 27, 2017.

[35] F. Yaya Bocoum, M. Grimm, and R. Hartwig, "The health care burden in rural Burkina Faso: consequences and implications for insurance design," SSM-Population Health, vol. 6, pp. 309-316, 2018.

[36] A. C. Liwa, L. R. Smart, A. Frumkin, H.-A. B. Epstein, D. W. Fitzgerald, and R. N. Peck, "Traditional herbal medicine use among hypertensive patients in sub-Saharan Africa: a systematic review," Current Hypertension Reports, vol. 16, no. 6, 437 pages, 2014.

[37] R. B. D’Agostino, M. J. Pencina, J. M. Massaro, and S. Coady, "Cardiovascular disease risk assessment: insights from Framingham," Global Heart, vol. 8, pp. 11-23, 2013.

[38] N. V. Yaméogo, A. Samadoulougou, L. J. Kagambèga et al., "Troubles du sommeil, symptômes anxio-dépressifs et risque cardio-vasculaire chez les hypertendus noirs africains: étude transversale de 414 hypertendus suivis en ambulatoire au CHU de Ouagadougou (Burkina Faso)," Pan African Medical Journal, vol. 21115 pages, 2015.

[39] A. Sawadogo, S. Sanou, A. Hema et al., "Syndrome métabolique et risque cardiovasculaire chez des patients sous antirétroviraux à l'hôpital de jour de Bobo-Dioulasso (Burkina Faso)," Bulletin de la Société de Pathologie Exotique, vol. 107, no. 3, pp. 151-158, 2014.

[40] L. Smith, "New AHA recommendations for blood pressure measurement," American Family Physician, vol. 721391 pages, 2005.

[41] Programme National de Lutte Contre les Maladies Non Transmissibles, Plan Stratégique Intégré de Lutte Contre Les Maladies Non Transmissibles 2016-2020, 2020. 